\title{
Seismic and aseismic fault slip before and during the 2011 off the Pacific coast of Tohoku Earthquake
}

\author{
Shin'ichi Miyazaki ${ }^{1}$, Jeffery J. McGuire ${ }^{2}$, and Paul Segall ${ }^{3}$ \\ ${ }^{1}$ Faculty of Science, Kyoto University, Kyoto, Japan \\ ${ }^{2}$ Geology and Geophysics Department, Woods Hole Oceanographic Institution, Woods Hole, MA, USA \\ ${ }^{3}$ Department of Geophysics, Stanford University, Stanford, CA, USA
}

(Received April 15, 2011; Revised June 30, 2011; Accepted July 1, 2011; Online published September 27, 2011)

\begin{abstract}
The March 11, 2011, off the Pacific coast of Tohoku Earthquake is the first great subduction zone earthquake to be recorded by a dense, modern network of geodetic quality Global Positioning System (GPS) receivers, and hence presents an unprecedented opportunity to study the evolution of fault slip during the time periods immediately before, during, and after a truly great earthquake. We utilized sub-daily GPS data to constrain the slip distribution in the March $9 M_{\mathrm{w}} 7.3$ foreshock, the 50-hour time period between the foreshock, and the coseismic slip during the $M_{\mathrm{w}} 9.0$ mainshock. We find that the foreshock ruptured downdip from its hypocenter, that there was considerable $\left(M_{\mathrm{w}} \sim 7.3\right)$ slip during the 50 hours between the foreshock and the mainshock, and that the peak mainshock slip was about $35 \mathrm{~m}$. The mainshock's epicenter may have been triggered by afterslip that followed the foreshock. Additionally, the mainshock slip distribution was centered further updip than the peak interseismic coupling estimated from GPS data in the ten years before the earthquake.
\end{abstract}

Key words: The 2011 Tohoku Earthquake, coseismic fault slip, aseismic fault slip, network strain filter.

\section{Introduction}

The 2011 off the Pacific coast of Tohoku Earthquake (March 11, 2011) is the first great subduction zone earthquake to be recorded by a dense, modern geodetic quality network of Global Positioning System (GPS) receivers, and hence presents an unprecedented opportunity to study the evolution of fault slip during the time periods immediately before, during, and after a truly great earthquake. The GPS Earth Observation Network (GEONET) (Miyazaki et al., 1997), which is operated by the Geospatial Information Authority (GSI) of Japan, consists of over 1200 stations within the Japanese islands, approximately 300 of which were located in Northern Honshu (Fig. 1) and provide direct constraints on the deformation leading up to, during, and following the 2011 Tohoku earthquake.

The off Tohoku region presents a spectacular opportunity to investigate the connections between seismic and aseismic fault slip. The interseismic coupling distribution was estimated by several groups using GEONET data prior to the earthquake (Nishimura et al., 2004; Hashimoto et al., 2009). Additional constraints on aseismic slip come from interpretation of repeating earthquakes (Uchida et al., 2003). Moreover, previous Japan Trench earthquakes have been followed by aseismic afterslip with a moment equal to, or larger than, the mainshock (e.g., Heki et al., 1997). Aseismic afterslip accounts for a considerable fraction of plate motion in some subduction zones (Heki et al., 1997;

Copyright (C) The Society of Geomagnetism and Earth, Planetary and Space Sciences (SGEPSS); The Seismological Society of Japan; The Volcanological Society of Japan; The Geodetic Society of Japan; The Japanese Society for Planetary Sciences; TERRAPUB.

doi:10.5047/eps.2011.07.001
Burgmann et al., 2001; Melbourne et al., 2002; Hsu et al., 2006) and provides fundamental constraints on faultzone rheology (Hetland and Simons, 2010; Montesi, 2004). Our goal in this paper is to utilize subdaily GPS data from GEONET to provide an unusually detailed view of the relationship between aseismic and seismic fault slip in the time period immediately surrounding a great megathrust rupture.

Utilizing continuous GPS time series to study aseismic fault slip is often complicated by colored noise in the time series (particularly at short ( $<1$ day) and seasonal time scales) that must be modeled either physically or statistically. Over the last fifteen years, a suite of Kalman filter based techniques have been developed for inverting GPS data that are capable of accounting for colored noise processes statistically and other common effects in these data such as reference frame errors in the GPS processing (Segall and Matthews, 1997; McGuire and Segall, 2003; Miyazaki et al., 2003; Ohtani et al., 2010). While the Network Inversion Filter (NIF) (Segall and Matthews, 1997) requires a specific fault model and elastic Green's functions, the Network Strain Filter (NSF) (Ohtani et al., 2010) uses the spatial coherence of the deformation in the data without requiring a fault model or Green's functions. Since a spatially coherent variation in the GPS time series may not be caused by crustal deformation alone, it may be a good idea to run the NSF to obtain the space-time variation of the signal prior to running the NIF. Here, we utilize the NSF and static finite-fault inversions to examine the space-time relationships between seismic and aseismic slip during the $\sim 10$ days before and after the 2011 Tohoku earthquake. 

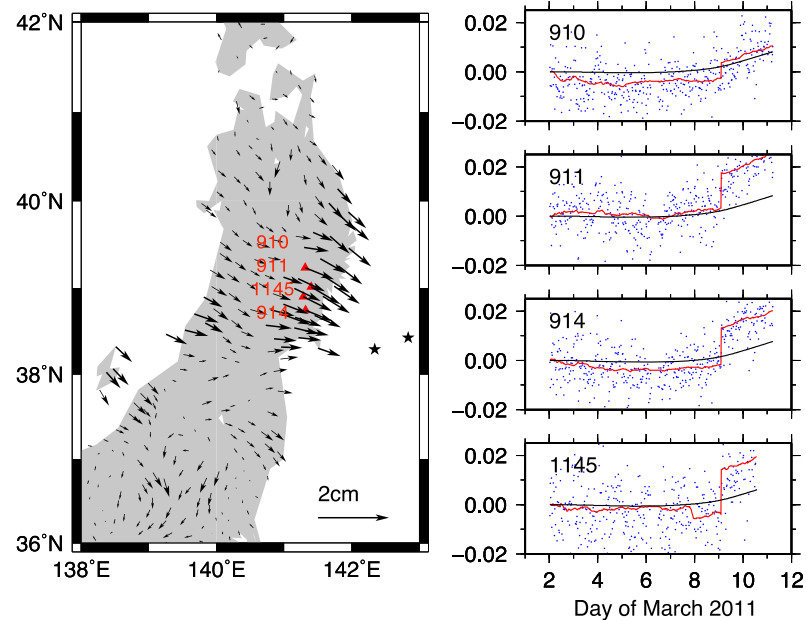

Fig. 1. Map gives the horizontal components of the transient deformation field between the time of the foreshock and the mainshock as estimated by the NSF. Panels on the right show the east component time series for the 4 stations denoted by the red triangles on the map with three or four digits of station code (910: Esashi, 911: Iwate-Ohigashi, 914: Miyagi-Towa, 1145: Iwate-Kawasaki-A). The blue dots are the JPL 30-min solutions minus our estimate of the reference frame error. The red line is the sum of the benchmark, transient, and Heaviside components of the time series as estimated by the NSF. The black curve is the transient deformation field as estimated by the filter. The $y$-axis of each time series plot is in meters.

\section{Application of the Network Strain Filter to the Pre-Mainshock GEONET GPS Data}

To investigate whether any aseismic deformation occurred before the March 9, $M_{\mathrm{JMA}} 7.3$ foreshock, or between the foreshock and the $M_{\mathrm{JMA}} 9.0$ March 11 mainshock, we utilized the Network Strain Filter (NSF) method developed by Ohtani et al. (2010). The NSF is a Kalman filter based algorithm for analyzing continuous GPS data that is capable of separating spatially coherent tectonic strain transients from various sources of noise in the GPS data. We used preliminary GPS displacement data (version 0.1 ), obtained by the ARIA team at JPL and Caltech by processing GEONET RINEX data. All of the original GEONET RINEX data was provided to Caltech by the Geospatial Information Authority (GSI) of Japan. We used 256 GPS stations (Fig. 1), with 430 30-min position determinations from 00:30:00 on March 2 (Julian day 61) 2011 till 05:30:00 on March 11, 2011 (UT), including approximately 7 days before the foreshock and about 51 hours of data between the foreshock and mainshock.

The state-space model used to analyze the GPS data is very similar to that described by Ohtani et al. (2010). For this relatively short data set, neither secular displacements nor seasonal variations are significant. However, we retain the site-specific benchmark (random walk) term in the statespace model because there is significant colored noise in the time series resulting from multipath and other effects that are not appropriately averaged out in the 30-min solutions. We include a Heaviside step function in the state-space model to account for the coseismic offsets at the time of the foreshock (Miyazaki et al., 2003). The spatially coherent transient deformation field is expanded in DeslauriersDubuc (DD) interpolating wavelet basis functions of degree
3 as in Ohtani et al. (2010); only the horizontal components of the GPS time series are analyzed because of significantly larger colored noise in the vertical. We determined an appropriate value of the spatial smoothing parameter $\lambda^{2}$ following the same method as in Ohtani et al. (2010). The scale factors, $\sigma$ and $\tau$, were set to $3 \mathrm{~mm}$ and 1 , based on inspection of the time series. The minimum scale of the wavelet basis function set was chosen as 3 which was determined to be sufficient to represent the transient field for the GEONET station spacing.

To eliminate tradeoffs between our estimates of the foreshock's coseismic displacement, postseismic displacement following the foreshock, and reference frame errors, we estimated corrections to the reference frame first and then fixed them a priori for the final NSF run. To estimate the reference frame terms (which are coherent over long spatial scales), we ran the NSF using only the stations in Fig. 1 that are located between $36^{\circ} \mathrm{N}$ and $38^{\circ} \mathrm{N}$ and those between $40.75^{\circ} \mathrm{N}$ and $42^{\circ} \mathrm{N}$. Essentially we excluded any stations that were likely to be affected by the foreshock and its afterslip. Owing to the modest spatial extent of the network, only the translational components of the reference frame error were estimated. Of particular significance for our result is an $\sim 5$-mm shift of the reference frame to the east in the JPL solutions that begins at the time of the foreshock and persists for about 10 hours. We subtracted the $a$ priori frame error estimates from the full data set before the final NSF run.

The transient deformation field between the foreshock and the mainshock as estimated by running the NSF on the full 254 station dataset is shown in Fig. 1. For the majority of sites distant from the rupture area (185 out of 254), the estimated transient deformation is $\leq 4 \mathrm{~mm}$, indicating that this is the effective noise level in the estimation process. These errors likely result from colored noise in the GPS time series that has sufficient spatial coherence to be mapped into the transient signal. However, for a small subset (23 of 254), the estimated spatially coherent transient deformation is $\geq 7 \mathrm{~mm}$. These stations are the same ones that show significant coseismic offsets $(1-2 \mathrm{~cm})$ at the time of the foreshock (Fig. 1), so we interpret these motions as actual crustal deformation. The solid black lines in Fig. 1 denote the transient signal, which appears to indicate that the aseismic deformation began before the foreshock. This is likely a well-known consequence of temporal smoothing during the "backsmoothing" run of the Kalman filter. There is no direct indication of any aseismic slip actually starting before the $M_{\mathrm{JMA}} 7.3$ foreshock during the forward run of the filter. Thus, the primary result of the NSF analysis is that a spatially coherent, aseismic deformation transient resulted in $7-10 \mathrm{~mm}$ of eastward motion during the 50 hours between the foreshock and the mainshock at the GPS sites near the east coast of Honshu between about $38.5^{\circ} \mathrm{N}$ and $39.5^{\circ} \mathrm{N}$. In contrast, the eastward motion observed along the Japan Sea Coast (Longitude 140.0E), with amplitude larger than the central Tohoku area (Longitude 140.7E) likely results from a combination of colored noise that is coherent between a few nearby stations and hence mapped into the smooth basis functions. 


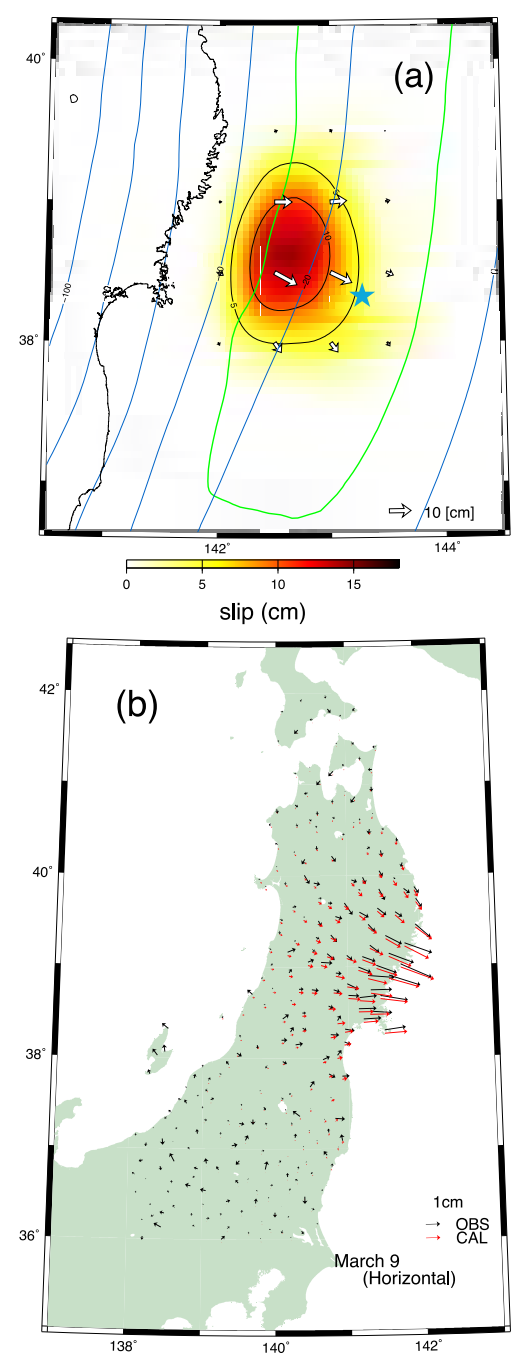

Fig. 2. (a) Foreshock slip distribution. The black, green and blues contours represent slip, its error, and depth of the plate interface. The interval of slip contour is $5 \mathrm{~cm}$. The error contour is $5 \mathrm{~cm}$. Note that error is scaled by the misfit. Error is larger in the inside of the contour, and is low near the trench because the slip there is constrained to be small. The maximum value of error is $8.7 \mathrm{~cm}$. The asterisk indicates the epicenter. (b) Fit to horizontal displacement data. Black and red arrows represent observed and predicted displacements.

\section{Finite Fault Slip Inversion}

$M>7.0$ aftershocks occurred shortly after the mainshock at 6:08 UTC and 6:15 UTC. GPS time series with 30min sampling do not provide sufficient temporal resolution to discriminate the mainshock from the large aftershocks. Therefore, we obtained station positions every 5 min using Precise Point Positioning as implemented in the GIPSYOASIS software. We confirmed that our solutions are consistent with the JPL solutions in a time range of a few hours around the mainshock. The coseismic displacements for the mainshock are obtained by differencing averaged positions during 5:25 and 5:45 UTC for the preseismic and 5:55 and 6:05 UTC for the postseismic. Coseismic displacements for the two $M>7.0$ aftershocks are obtained by taking the difference of the averages of 5:55-6:05 and 6:20-6:40 UTC.

We then invert the obtained displacement fields associated with the foreshock on March 9, the mainshock on March 11, the two $M>7.0$ aftershocks, and the possible

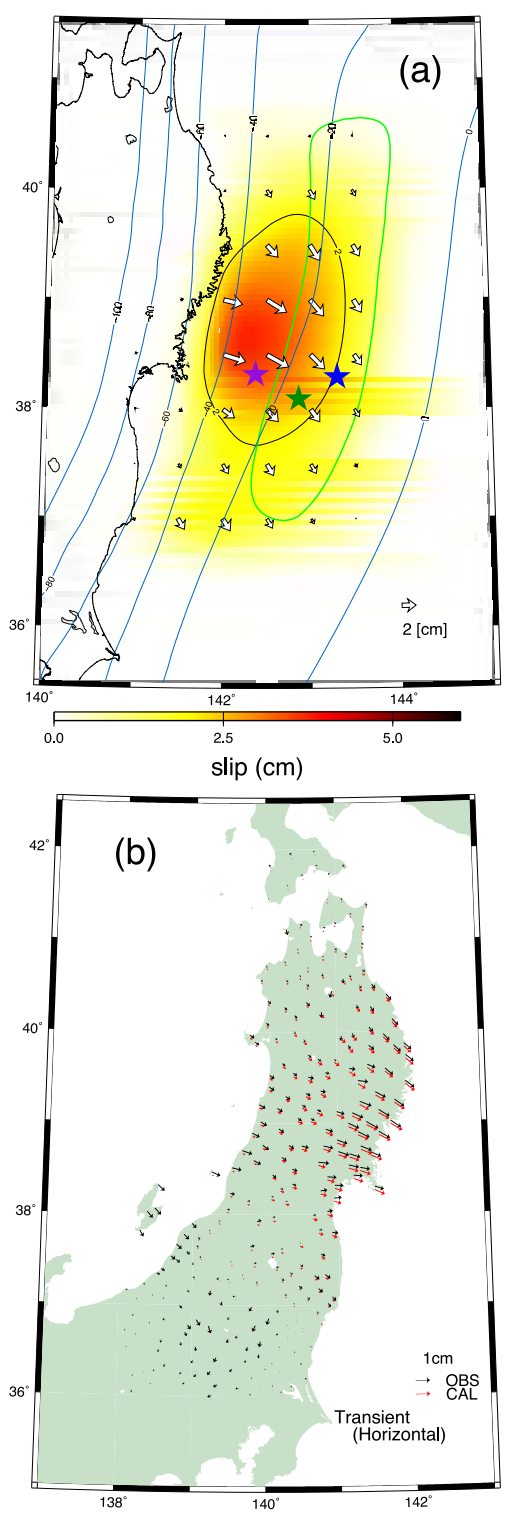

Fig. 3. (a) Transient slip distribution, The black, green and blues contours represent slip, its error and depth of the plate interface. The slip contour is $2.0 \mathrm{~cm}$, and the error contour is $1.5 \mathrm{~cm}$. Note that error is scaled by the misfit. Error is larger in the inside of the contour, and is low near the trench because the slip there is constrained to be small. The maximum value of error is $1.9 \mathrm{~cm}$. The black, green and blue contours represent slip, standard deviation of slip and depth of the plate interface. The blue asterisk shows the epicenter of the March 9 foreshock, and the green and purple asterisks indicate the epicenter of the March 11 mainshock by JMA and USGS, respectively. (b) Fit to horizontal displacement data. Black and red arrows represent observed and predicted displacements.

transient deformation between the foreshock and the mainshock, which we term 'the transient' for simplicity. We employ the isodepth contours of the subducting slab from Baba et al. (2006) to specify the fault geometry. The model region is subdivided into a set of triangles. The side length of each triangle is $25 \mathrm{~km}$ for the mainshock and $20 \mathrm{~km}$ for the other inversions. We employ triangular dislocations in an elastic half-space (Andy Thomas MS thesis, Stanford University) which tessellate the plate interface. Laplacian smoothing is imposed, with weighting relative to the data residuals determined by minimizing the Akaike Bayesian Information Criteria (ABIC) (Akaike, 1974). Non-negative 

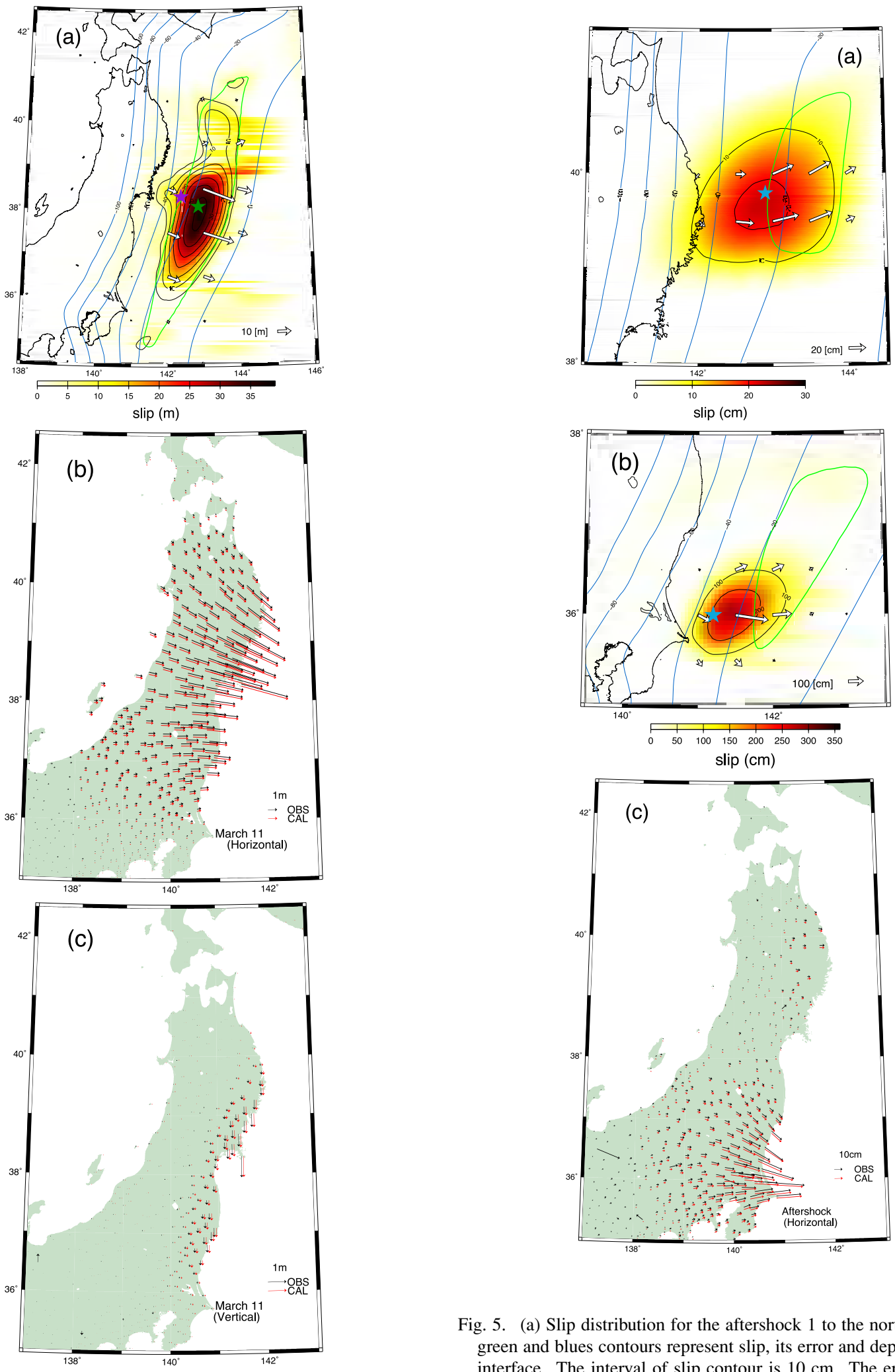

Fig. 5. (a) Slip distribution for the aftershock 1 to the north. The black, green and blues contours represent slip, its error and depth of the plate interface. The interval of slip contour is $10 \mathrm{~cm}$. The error contour is $10 \mathrm{~cm}$. The black, green and blue contours represent slip, standard deviation of slip and depth of the plate interface. Note that error is scaled by the misfit. Error is larger in the inside of the contour, and is low near the trench because the slip there is constrained to be small. The maximum value of error is $19 \mathrm{~cm}$. The asterisk indicates the epicenter. (b) Similar figure for the aftershock 2 to the south. The interval of slip contour is $1.0 \mathrm{~m}$. The error contour is $0.75 \mathrm{~m}$. The maximum value of error is $1.0 \mathrm{~m}$. (c) Fit to horizontal displacement data. Black and red arrows represent observed and predicted displacements. of error is $8.9 \mathrm{~m}$. The green and purple asterisks indicate the epicenter of the March 11 mainshock by JMA and USGS, respectively. (b) Fit to three dimensional displacement data. Black and red arrows represent observed and predicted displacements.

Fig. 4. (a) Coseismic slip distribution. The black, green and blues contours represent slip, its confidence interval and depth of the plate interface. black, green and blue contours represent slip, standard deviation of slip and depth of the plate interface. Note that error is scaled by the misfit. Error is larger in the inside of the contour, and is low near the trench 
least squares is used in the inversion for the foreshock and transient slip distributions because the signal to noise ratios are small enough for these cases to benefit from this constraint. We estimated slip in the directions of rake $=45$ and 135 and imposed positivity for both, hence slip is restricted in the direction of plate subduction direction \pm 45 . We followed Yabuki and Matsu'ura (1992) to evaluate the error of slip estimates.

We present the slip distributions in chronological order. The slip during the foreshock is shown in Fig. 2(a). The peak slip is about $12 \mathrm{~cm}$ at around $(142.75,38.6)$ and the moment magnitude is $M_{\mathrm{w}} \sim 7.1$. The uncertainty is less than $8.7 \mathrm{~cm}$. The maximum slip is found to occur deeper than the epicenter $(143.3,38.3)$ (JMA, 2011). The fit to the GPS offsets is shown in Fig. 2(b).

The cumulative slip during the transient between the foreshock and the mainshock, including both aseismic slip and any smaller earthquakes during this time period, is shown in Fig. 3(a). The eastward deformation along the Pacific Coast area is consistent with slip on the thrust interface. The peak of the slip is found around $(142.0,38.6)$, closer to the coast than the peak of the slip for the foreshock. The uncertainty is smaller than $1.9 \mathrm{~cm}$, so the signal is significant. The data fit is shown in Fig. 3(b). Stations along the Japan Sea Coast have eastward trend, but they do not affect the inversion very much as they are essentially not fit by the result (Fig. 3(b)). The moment magnitude of the transient is $M_{\mathrm{w}} \sim 7.0$, but this may be a slight overestimate due to the spatial smoothing inherent in the NSF. The concentration of the transient afterslip in a region downdip of the foreshock's epicenter and peak-slip region is similar to previous observations for the 1994 Sanriku Haruka-oki earthquake (Yagi et al., 2003) which was located just north of the 2011 Tohoku earthquake, and the 2003 Tokachi-oki earthquake (e.g., Miyazaki and Larson, 2008) located further north on the Kurile Trench. Since the maximum of the transient slip distribution is found to be close to the USGS epicenter for the 2011 Tohoku earthquake, it is possible that the foreshock's afterslip promoted the initiation of the mainshock's rupture.

The slip distribution for the mainshock is shown in Fig. 4(a). The data fit is shown in Fig. 4(b). Slip at a shallow depth near the trench is extremely poorly resolved by the on-shore geodetic data. The result here is tapered to zero slip at the trench; inversions without this constraint find unrealistically large slip in this area. It should be noted that 5-min GPS solutions involve less afterslip and/or coseismic slip associated with aftershocks compared to the daily GPS solutions. With these data the coseismic slip during large aftershocks can be separated from the slip for the mainshock. The peak slip is found near the JMA epicenter (142.86, 38.10) (JMA, 2011), at a significantly shallower region than the USGS epicenter $(142.37,38.32)$ (USGS, 2011). The slip amplitude is about $35 \mathrm{~m}$, one order of magnitude larger than other recent thrust events such as the 1978 off-Miyagi earthquake (e.g., Yamanaka and Kikuchi, 2004). The uncertainty is less than $8.9 \mathrm{~m}$. The slip distribution extends both to the north and south, suggesting that the mainshock ruptured bilaterally.

Two $M>7.0$ aftershocks occurred at 6:08 and 6:15 UTC around the northern and southern edges of the main rupture zone, respectively. We term them "aftershock 1" and "aftershock 2", respectively. We successfully estimated the coseismic displacements associated with those aftershocks and inverted them for the slip distribution using the same approach as for the mainshock. Because the vertical component data do not exhibit significant displacement compared to their scatter, we did not use them in the inversion. The inferred slip distributions are shown in Fig. 5(a) and the fits are shown in Fig. 5(b). The slip in aftershock 1 is found around the northern edge of the main rupture region, and its moment magnitude is estimated to be 7.5. The slip in aftershock 2 is located around the southern edge of the mainshock, and its moment magnitude is 7.8. Peaks in the slip distribution are both larger than the standard deviation.

\section{Discussion}

Our inversion results present the following scenario for the space-time evolution of fault-slip during March 9-11. First the $M_{\mathrm{w}} \sim 7.3$ foreshock occurred on March 9. Significant afterslip followed for the next $\sim 50$ hours in a region slightly downdip of the foreshock's rupture zone. This transient aseismic slip may have contributed to loading the epicentral region of the mainshock. It appears that the mainshock nucleated within the transient slip zone, but given the small amplitude of the transient and the poor spatial resolution this should be viewed with caution. The mainshock rupture propagated both updip and also bilaterally to the north and south. About 20-30 min later, two $M>7.0$ aftershocks occurred at the both the northern and southern edges of the rupture area. It is likely that regions further north/south of the aftershocks have been loaded by both mainshock and the aftershocks.

There are several remarkable features in the inferred slip distributions. We first compare the coseismic slip for the mainshock with the rate of the interseismic slip deficit (e.g., Hashimoto et al., 2009). Clearly the peak mainshock slip is shallower than the inferred maximum of the preearthquake coupling distribution. Secondly, the amplitude of the mainshock slip is one order of magnitude larger than $M \geq 8.0$ earthquakes that occurred recently at the Japan Trench (Yamanaka and Kikuchi, 2003). A similar feature was observed for the 2004 Sumatra earthquake, the peak slip of which was inferred to be $\sim 30 \mathrm{~m}$. Thirdly, significantly smaller earthquakes, such as the 1978 off-Miyagi earthquake, have occurred inside of the rupture region of the mainshock. Several interesting questions arise from this set of observations: (1) Was the shallow plate interface locked during the interseismic period including immediately prior to the earthquake, but simply was not visible with GPS measurements inland, or was the plate coupling actually weak immediately before the earthquake? If the latter is correct, does the plate coupling vary in time? (2) Why were ruptures for smaller earthquakes ( $M \sim 7 \sim 8$ ) which nucleated in the hypocentral area arrested even though the fault was near the end of its seismic cycle? (3) What controls the cumulative seismic slip? Studies of tsunami deposits have suggested that there was at least one similar giant event (the 869 Jogan earthquake) (Satake et al., 2008). They further point out the possibility of another similar giant event after the 
Jogan earthquake. Thus, asperities that fail in $M \sim 7 \sim 8$ earthquakes slip only several meters when these ruptures occur but displace more than 10 meters during giant earthquakes.

Another important question is whether there was a preseismic transient. In this paper, we focus on only the 10 days before the earthquake to investigate possible shortterm preseismic transients. In this particular case, a $M_{\mathrm{w}} 7.3$ earthquake occurred on March 9, just two days before the 2011 Tohoku earthquake. We were able to identify a spatially coherent signal in kinematic GPS time series between the foreshock and mainshock using the NSF and we interpret this deformation to result principally from afterslip following the $M_{\mathrm{w}} 7.3$ earthquake on March 9. Although it is likely that the eastward deformation in the Pacific Coast results from the afterslip of the March 9, $M_{\mathrm{w}} 7.3$, earthquake, it is presently unclear whether there was unusual slip leading up to the $M 9$ mainshock. Certainly, a more detailed investigation of this signal in the data and its role in the mainshock is warranted.

Acknowledgments. We appreciate Dr. Takuya Nishimura and an anonymous reviewer for critical and constructive comments, Prof. Kiyoshi Yomogida and Prof. Hiroo Kanamori for their editorship. Figures were created with the GMT software by Paul Wessel and Walter H. F. Smith. This research was partially supported by the Ministry of Education, Science, Sports and Culture, Grant-in-Aid for Scientific Research (B), 21340127, 2009-2011.

\section{References}

Akaike, H., A new look at the statistical model identification, IEEE Trans. Automatic Control, 19, 716-723, 1974.

Baba, T., A. Ito, Y. Kaneda, T. Hayakawa, and T. Furumura, 3-D seismic wave velocity structures in the Nankai and Japan Trench subduction zones derived from marine seismic surveys, Abstract of the Meeting of Japan Geoscience Union, 2006 (in Japanese with English abstract).

Bürgmann, R., M. G. Kogan, V. E. Levin, C. H. Scholz, R. W. King, and G. M. Steblov, Rapid aseismic moment release following the 5 December, 1997 Kronotsky, Kamchatka, earthquake, Geophys. Res. Lett., 28, 1331-1334, 2001.

Hashimoto, C., A. Noda, T. Sagiya, and M. Matsu'ura, Interplate seismogenic zones along the Kuril-Japan trench inferred from GPS data inversion, Nature Geosci., 2, 141-144, 2009.

Heki, K., S. Miyazaki, and H. Tsuji, Silent fault slip following an interplate thrust earthquake at the Japan Trench, Nature, 386, 595-598, 1997.

Hetland, E. A. and M. Simons, Post-seismic and interseismic fault creep II: transient creep and interseismic stress shadows on megathrusts, Geophys. J. Int., 181, 99-112, 2010.

Hsu, Y. J., M. Simons, J. P. Avouac, J. Galetzka, K. Sieh, M. Chlieh, D. Natawidjaja, L. Prawirodirdjo, and Y. Bock, Frictional afterslip following the 2005 Nias-Simeulue earthquake, Sumatra, Science, 312, 1921-
1926, 2006.

Japan Meteorological Agency, http://www.jma.go.jp/jma/press/1103/ 25b/201103251730.html, 2011.

McGuire, J. J. and P. Segall, Imaging of aseismic fault slip transients recorded by dense geodetic networks, Geophys. J. Int., 155, 778-788, 2003.

Melbourne, T. I., F. H. Webb, J. M. Stock, and C. Reigber, Rapid postseismic transients in subduction zones from continuous GPS, J. Geophys. Res., 107(B10), 2241-2250, 2002.

Miyazaki, S. and K. M. Larson, Coseismic and early postseismic slip for the 2003 Tokachi-oki earthquake sequence inferred from GPS data, Geophys. Res. Lett., 35, L04302, doi:10.1029/2007GL032309, 2008.

Miyazaki, S., T. Saito, M. Sasaki, Y. Hatanaka, and Y. Iimura, Expansion of GSI's nationwide GPS array, Bull. Geogr. Surv. Inst., 43, 23-34, 1997.

Miyazaki, S., J. J. McGuire, and P. Segall, A transient subduction zone slip episode in southwest Japan observed by the nationwide GPS array, J. Geophys. Res., 108(B2), 15, 2003.

Montesi, L. G. J., Controls of shear zone rheology and tectonic loading on postseismic creep, J. Geophys. Res., 109(B10), 18, 2004.

Nishimura, T., T. Hirasawa, S. Miyazaki, T. Sagiya, T. Tada, S. Miyra, and K. Tanaka, Temporal change of interplate coupling in northern Japan during 1995-2002 estimated from continuous GPS observations, Geophys. J. Int., 157, 901-916, 2004.

Ohtani, R., J. J. McGuire, and P. Segall, Network strain filter: A new tool for monitoring and detecting transient deformation signals in GPS arrays, J. Geophys. Res., 115, B12418, doi:10.1029/2010JB007442, 2010.

Satake, K., Y. Namegaya, and S. Yamaki, Numerical simulation of the AD 869 Jogan tsunami in Ishinomaki and Sendai plains, Ann. Rep. Active Fault Paleoearthq. Res., 8, 71-89, 2008 (in Japanese with English abstract).

Segall, P. and M. Matthews, Time dependent inversion of geodetic data, $J$. Geophys. Res., 102, 22391-22409, 1997.

Thomas, A. L., POLU3D: A three-dimensional, polygonal element, displacement discontinuity boundary element computer program with applications to fractures, faults, and cavities in the earth's crust, Master Thesis at Stanford University, 1993.

Uchida, N., T. Matsuzawa, A. Hasegawa, and T. Igarashi, Interplate quasistatic slip off Sanriku, NE Japan, estimated from repeating earthquakes, Geophys. Res. Lett., 30, doi10.1029/2003GL017452, 2003.

USGS, Magnitude 9.0-Near the east coast of Honshu, Japan, http://earthquake.usgs.gov/earthquakes/eqinthenews/2011/usc0001xgp, 2011.

Yabuki, T. and M. Matsu'ura, Geodetic data inversion using a Bayesian information criterion for spatial distribution of fault slip, Geophys. J. Int., 109, 363-375, 1992.

Yagi, Y., M. Kikuchi, and T. Nishimura, Co-seismic slip, postseismic slip, and largest aftershock associated with the 1994 Sanriku-haruka-oki, Japan, earthquake, Geophys. Res. Lett., 30, 2177, doi:10.1029/2003GL018189, 2003.

Yamanaka, Y. and M. Kikuchi, Asperity map along the subduction zone in northeastern Japan inferred from regional seismic data, J. Geophys. Res., 109, B07307, doi:10.1029/2003JB002683, 2004.

S. Miyazaki (e-mail: shinichi.miyazaki@kugi.kyoto-u.ac.jp), J. J. McGuire, and P. Segall 